\title{
Theoretical Research on the Reactive Power Compensation Converter
}

\author{
Lin Feng, Lingyan Shi, Xiangsheng Huang, Zhirong Fan \\ East China Institute of Technology, Fuzhou City, Jiangxi Province, China, 344000
}

\begin{abstract}
The article proposes a novel form of reactive power compensation converter, which adopts an inverter consisted of up and down symmetrical basic units and bidirectional switch. In this work, we have studied the working principle and operation characteristic of this circuit. According to the experimental results, this circuit has many superior performances, such as the output waveform traversing zero smoothly, the less waveform distortion and perfect stability of the frequency and magnitude.
\end{abstract}

Keywords-converter; inverter; waveform distortion; stability of frequency and magnitude.

\section{INTRODUCTION}

In the 1990s, the researches of power electronics were mostly limited to the SCR(silicon controlled rectifier) phase control frequency converter and matrix converter in terms of $\mathrm{AC} / \mathrm{AC}$ converter technique without electric isolation between $\mathrm{AC}$ load and $\mathrm{AC}$ power grid . In recent years, the researches focus on the isolated AC/AC direct conversion, which includes high frequency electrical isolation between AC load and AC power grid. Although researches on isolated $\mathrm{AC} / \mathrm{AC}$ is very significant to achieve new type electronic transformer and regulated sinusoidal ac power supply, the solution of AC/AC direct conversion has a few flaws that it can only achieve reactive power from the power grid, which load generate or need. With a wide range of applications of electrical equipment, it is bound to exert influence to the frequency stability of the power grid. Therefore, the new generation of transformer not only has the characteristics of high frequency and miniaturization, but also it has the capacity of producing/releasing reactive power. This new type of isolated $\mathrm{AC} / \mathrm{AC}$ electronic converter Equipped with the above two characteristics was defined as reactive power compensation converter.

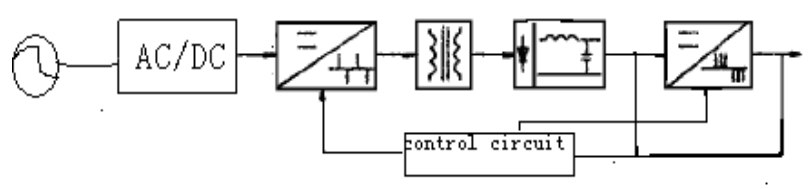

\section{A NOVEl CONVERTER SYSTEM}

Figure 1. The function block diagram of the reactive power compensation converter

Figure 1 shows the function blocks' diagram of the reactive power compensation converter device.

Foundation item: National Natural Science Foundation of China (NSFC)(Project name: Research on the key technology of intelligent electric appliances control based on SOPC, Grant No r: 61161010)

The Author Introduction: Lin Feng (1971.03-), male, Associate professor. Research Area: Embedded Technology

According to the division of circuit function, control circuit can be divided into the following several parts: sine signal generate circuit with high stability and low distortion, sine pulse width modify (SPWM) signal generator, feedback protection circuit etc. But, need to point out that SPWM inverter should be equipped with a generator used to release/absorb reactive power, which is purposed to achieve the good match between device and load as well as reduce the influence of load on the environment.

\section{CIRCUIT TOPOLOGICAL STRUCTURE AND PRINCIPLE OF OPERATION}

To solve the problem of traversing zero smoothly, the voltage output by two basic units which are up and down symmetrical. When the voltage of the two units $U_{01}$ is equal to $U_{02}$, the output of the overall circuit $U_{0}$ is $0 \mathrm{~V}$, which is adjusted by single-stage SPWM converting. The output voltage of the circuit could traverse zero smoothly, as shown in Figure 2.

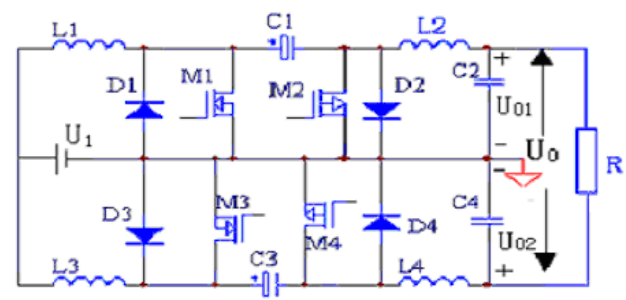

Figure 2. The basic structures of a novel DA/AC power inverter

In basic structures of the novel DA/AC power inverter, M1、M2、M3 and M4 are paired power tubes with a pair of complementary signals controlling them. In figure 2 , we assumed that $D_{1} 、 D_{2}$ are the conduction duty cycle of the up and down symmetrical basic units convertor, and $D_{1}+D_{2}=1$, due to input-parallel and output-series, therefore the function equation of power converter is given by

$$
U_{o}=U_{1} * \frac{2 D_{1}-1}{D_{1}\left(1-D_{1}\right)}
$$


The constructed function relation is simulated with MATLAB. The simulation results verify that a good linearity of the curve is existed at the HneighbourhoodH of $D_{1=0.5}$. For this reason, we set converter modulation rate near 0.5 , which can effectively overcome the problem of zero distortion.

Because the converter is required to properly process the reactive power. Figure 3 shows the basic structure block diagram of the assumed SPWM converter.

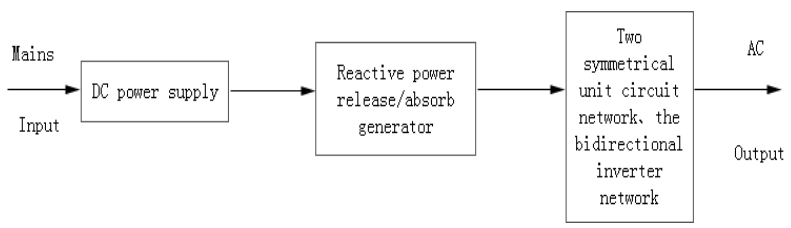

Figure 3. The basic structure block diagram of SPWM converter.

In addition, on the basis of characteristics of SPWM, as we know, the frequency of the inverter's output voltage depends on the frequency of the modulation signal in SPWM modulation inverter. How to design a high stability of the modulating signal source to meet the requirements of standard power supply for frequency stability is becoming crucial.

In terms of system control strategy, in order to guarantee the steady-state accuracy of the output and the waveform distortion of the output voltage can meet the performance requirements, control system consist of current feedback of capacitor as inner loop and output voltage as outer loop, as shown in Figure 4. In figure 4, L is a filter inductor, $\mathrm{C}$ is a filter capacitor. $R_{L}$ and $L_{L}$ are loads. After adopting current feedback of the capacitor, the transfer function of the output voltage is given by

$$
G_{U_{C}}(s)=\frac{1}{C s} \frac{K_{p i 2} G_{i c}(s)}{1+K_{p i 2} G_{i c}(s)}
$$

Where

$$
G_{i c}(s)=\frac{I_{c}(s)}{U_{m}(s)}=\frac{\left(E_{d c} / U_{t}\right) C s\left(R_{L}+s L_{L}\right)}{L C L_{L} s^{3}+L C R_{L} s^{2}+\left(L+L_{L}\right) s+R_{L}}
$$

Considering that there is still several small inertia links to affect the stabilization and dynamic features of the system in practice, we could modestly reduce $\mathrm{K}_{\mathrm{PI}}$ to improve the stabilization and satisfactory dynamic characteristics. When $\mathrm{K}_{\mathrm{PI}}=8$, phase margin is $57^{\circ}$ and gain margin is $74 \mathrm{~dB}$. But the decrease of $\mathrm{K}_{\mathrm{PI}}$ will increase the steady-state error of the output voltage, we could use PI mediator to remove the static errors.

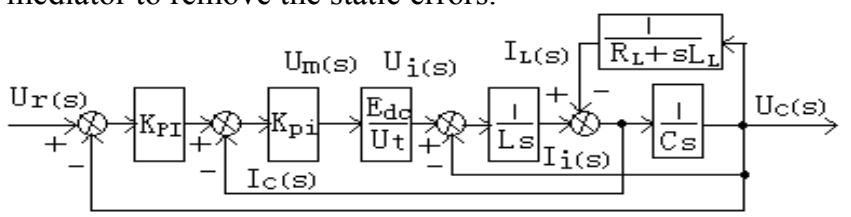

Figure 4. A block diagram of the control system with current and voltage feedback of filter capacitor

\section{THE SIMULATION ANALYSIS AND EXPERIMENTAL RESULT}

The experimental data: $\mathrm{L} 1=\mathrm{L} 2=\mathrm{L} 3=\mathrm{L} 4=12 \mathrm{mH}$; $\mathrm{C} 1=\mathrm{C} 3=1000 \mu \mathrm{F}$; the frequency of the modulation signal is sine wave with $50 \mathrm{~Hz}$. In fact, the measurement results of wave frequency are $30.5 \mathrm{kHz}$. In figure 5 , the ideal output voltage waveform comes from the voltage source of testing instrument whose accuracy grade is level 0.1 ; In this diagram, when $\mathrm{R}=50 \Omega, \mathrm{L}=150 \mathrm{mH}, \theta=44.3$, the practical curve is the output voltage or the electric wave.

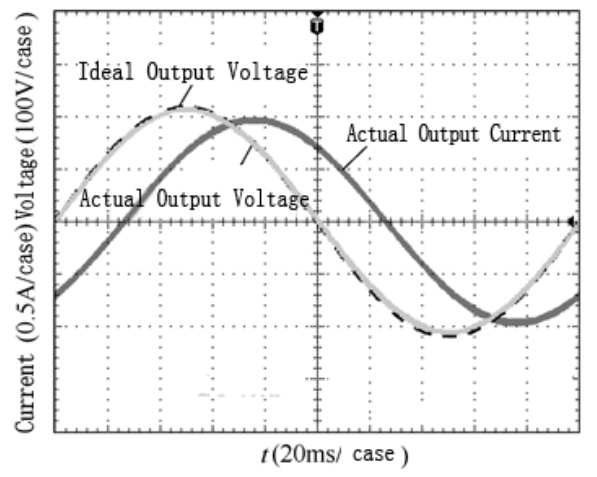

Figure 5. The waveform of the output voltage or current

From the above experimental results, the actual value of the output voltage is in a good agreement with the theoretical one.

\section{CONCLUSION}

In conclusion, the reactive power compensation converter based on the theory of modern power electronic technology is highly realistic and feasible at present. The meaning of the reactive power compensation converter study is that the convert can absorb and release reactive power by itself as well as reduce the influence of the load on the environment to meet the requirement of strong inductive loads. Therefore, one of the green power requirements(according to the characteristics of the load) can be achieved, which could perfectly match between power supply and load. So, it may be widely used, even including pollution-free and environmental-friendly vehicles which are forced by power grid directly, such as city trams and electric vehicles.

\section{ACKNOWLEDGMENTS}

The research work was supported by National Natural Science Foundation of China under Grant No. 61161010(National Natural Science Fund project: key technology research of smart appliances control based on SOPC).

\section{REFERENCES}

[1] Wang Z A .Power Electronic Technique （Release 4) [M]. Beijing: Machinery Industry Press, 2000

[2] Chu B.The application of power integrated chip. EE,2004,30(10) $33-35$ 
[3] Bao N L, Ning L G, Lin T, Guo J C. The research of a scheme about embedded control system [J]. Microcomputer, 2005, 21(16):6264.

[4] Yang X Y. The Principle and System of Motor Drives. Beijing: Water Conservancy and Electric Power Press, 1979

[5] Hu M X, Xie Y X. Analysis and Design of a Soft-Switching Boost-PFC circuit. Power Electronic Technique ,2007,41(8):
$19-21$.

[6] The Author Introduction: Lin Feng (1971.03-), male, Associate professor. Research Area: Embedded Technology

[7] Address:( School of Mechanical and Electronic Engineering, East China Institute Of Technology, Fuzhou City, Jiangxi Province, China, 344000 ) Telephone: 13879493001 